\title{
Atmospheric emission of polychlorinated naphthalenes from iron ore sintering processes
}

\author{
Guorui Liu ${ }^{a}$, Minghui Zheng ${ }^{\mathrm{a}, *}$, Bing Du ${ }^{\mathrm{a}, \mathrm{b}}$, Zhiqiang Nie ${ }^{\mathrm{a}}$, Bing Zhang ${ }^{\mathrm{a}}$, Wenbin Liu ${ }^{\mathrm{a}}$, Cheng $\mathrm{Li}^{\mathrm{a}}$, \\ Jicheng $\mathrm{Hu}^{\mathrm{a}}$ \\ a State Key Laboratory of Environmental Chemistry and Ecotoxicology, Research Center for Eco-Environmental Sciences, Chinese Academy of Sciences. P.0. Box 2871, \\ Beijing 100085, China \\ ${ }^{\mathrm{b}}$ State Environmental Protection Key Laboratory of Dioxin Pollution, National Research Center for Environmental Analysis and Measurement, Beijing 100029, China
}

\section{H I G H L I G H T S}

- PCN emissions from sintering processes were identified and quantified.

- The derived emissions factors were significant for developing a PCN inventory.

- The PCN profiles were dominated by lower chlorinated homologs.

- The congener characteristics could be used to identify PCN sources.

- The annual PCN emissions from sintering processes were estimated.

\section{A R T I C L E I N F O}

\section{Article history:}

Received 18 October 2011

Received in revised form 16 April 2012

Accepted 19 May 2012

Available online 25 June 2012

\section{Keywords:}

Polychlorinated naphthalenes

Emission inventory

Iron ore sintering

Persistent organic pollutants

Stockholm Convention
G R A P H I C A L A B S T R A C T

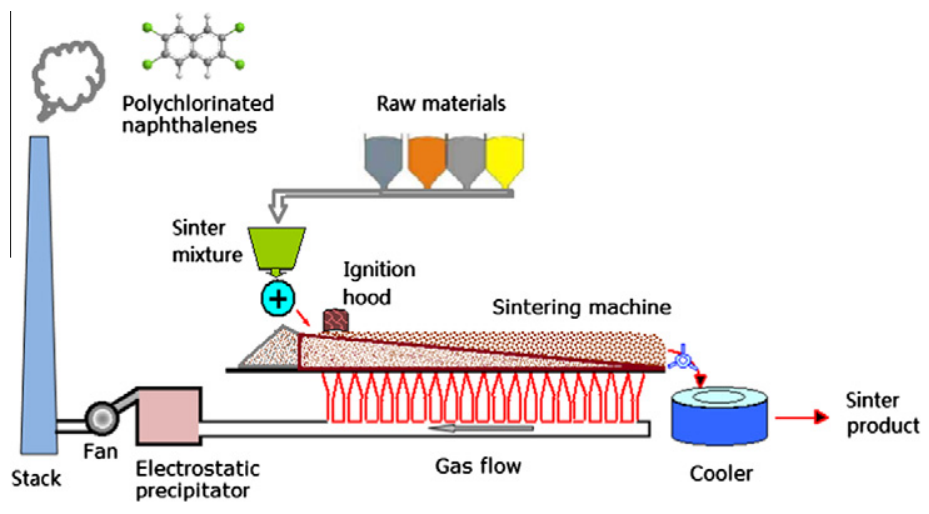

\section{A B S T R A C T}

Iron ore sintering processes constitute significant sources of dioxins, and studies have confirmed a close correlation between polychlorinated naphthalenes (PCNs) and dioxin formation. Thus, iron ore sintering processes are thought to be a potential source of PCNs, although intensive investigations on PCN emissions from sintering processes have not been carried out. Therefore, the aim of the present study was to qualify and quantify PCN emissions from nine sintering plants operating on different industrial scales. PCN concentrations ranged from 3 to $983 \mathrm{ng} \mathrm{m}^{-3}\left(0.4-23.3 \mathrm{pg} \mathrm{TEQ}_{\mathrm{PCN}} \mathrm{m}^{-3}\right)$ and emission factors ranged from 14 to $1749 \mu \mathrm{g} \mathrm{t}^{-1}\left(0.5-41.5 \mathrm{ng} \mathrm{TEQ}_{\mathrm{PCN}} \mathrm{t}^{-1}\right)$, with a geometric mean of $84 \mu \mathrm{g} \mathrm{t}^{-1}\left(2.1 \mathrm{ng} \mathrm{TEQ}_{\mathrm{PCN}} \mathrm{t}^{-1}\right)$. The estimated annual emission of PCNs from sintering processes in China was $1390 \mathrm{mg}$ TEQ figures will assist in the development of a PCN emissions inventory. Regarding emission characteristics, PCNs mainly comprised low-chlorinated homologs. The ratios of several characteristic PCN congeners were also measured and compared with those from other sources. Taken together, these results may provide useful information for identifying the sources of PCNs produced by iron ore sintering processes.

(ㄷ) 2012 Elsevier Ltd. All rights reserved.

\footnotetext{
* Corresponding author. Tel.: +86 106284 9172; fax: +86 1062923563.

E-mail address: zhengmh@rcees.ac.cn (M. Zheng).
}

\section{Introduction}

Polychlorinated naphthalenes (PCNs) are candidate persistent organic pollutants (POPs) according to the POP Protocol of the 
United Nations Economic Commission for Europe (UN-ECE) (Lerche et al., 2002). Furthermore, PCNs have recently been proposed for inclusion in Annexes A, B and/or C to the Stockholm Convention, 2011. Thus, PCNs have been attracting increased attention, and their ubiquitous presence in environmental matrices and biota has been intensively investigated (Domingo, 2004; Helm et al., 2004; Harner et al., 2006; Bidleman et al., 2010).

PCNs show similar toxicity to that of polychlorinated dibenzop-dioxins and dibenzofurans (PCDD/Fs), and are often referred to as dioxin-like compounds (Blankenship et al., 2000; Villeneuve et al., 2000). The relative potency factor (RPF) for individual PCN congeners have been estimated in comparison with 2378-TeCDD, and are used for toxicity evaluations for PCNs (Noma et al., 2004; Guo et al., 2008). A recent study shows that the toxic equivalents of $\mathrm{PCNs}\left(\mathrm{TEQ}_{\mathrm{PCN}}\right)$ are comparable with those of PCDD/Fs in some human serum samples (Park et al., 2010). The PCN TEQ ${ }_{P C N}$ in biota from polar environments accounts for about $10 \%$, or more, of the total TEQ of PCDD/Fs, dl-PCBs and PCNs (Bidleman et al., 2010). Studies by Kannan et al., show that PCNs comprise a greater proportion of dioxin-like toxicity in soil, sediment and biota in some areas surrounded by typical industrial plants than PCDD/Fs and PCBs (Kannan et al., 1998, 2001).

Identification and quantification of PCN emissions from anthropogenic activities represents the primary step in achieving source reduction. PCNs were produced and used as industrial chemicals years ago, and also occur as impurities in commercial PCB mixtures (Falandysz, 1998; Yamashita et al., 2000). The manufacture and use of PCNs and PCBs has been banned for decades, suggesting that the current sources of PCNs may be from unintentional formation/ emissions from industrial activities.

Iron ore sintering processes are significant sources of PCDD/Fs (Cieplik et al., 2003; Abad et al., 2004; Aries et al., 2006). Similar pathways of PCDD/Fs and PCN formation from thermal-related processes have been confirmed by some studies (Iino et al., 1999; Imagawa and Lee, 2001; Weber et al., 2001; Oh et al., 2007). Thus, it is speculated that iron ore sintering processes may be a significant PCN source, although intensive investigations into PCN emission from iron ore sintering processes have not been carried out.

China is one of the largest producers of sintering ore (622 million tonnes in 2009), and has many sintering plants operating on different industrial scales. Thus, studies of PCN emissions from Chinese sintering plants would facilitate the evaluation of PCN release from iron ore sintering processes worldwide.

The primary aim of the present study was to examine the emission factors and characterize the emission profiles of PCNs emitted by iron ore sintering processes. Nine iron ore sintering plants were selected and the PCN emissions identified and quantified. These data will be helpful for developing a PCN emission inventory and for identifying specific PCN sources from iron ore sintering processes.

\section{Materials and methods}

\subsection{Sampling of stack gas released from investigated sintering processes}

Nine sintering plants were investigated and the level and profile of PCN emissions characterized. The iron ore sintering processes were belt-type continuous sintering operations and the capacity of the nine plants ranged from 100 to 600 tonnes per hour. The flow rate of the stack gases ranged from 318800 to $1015900 \mathrm{~m}^{3} \mathrm{~h}^{-1}$ and the gas temperature at the sampling points ranged from about 80 to $130^{\circ} \mathrm{C}$. An electrostatic precipitator was used for gas cleaning before emission into the atmosphere via the main stack. The basic information concerning the nine sintering plants is shown in
Table 1. A detailed description and schematics showing the iron ore sintering process are provided in the Supplementary material.

Stack gas samples were collected using an automatic isokinetic sampling system (TCR TECORA, Italy) and the methods used are described in detail in our previous studies (Ba et al., 2010; Liu et al., 2010). Briefly, the sampling train comprised a heated probe, a filter box equipped with a quartz fiber filter, and a water-cooled XAD-2 adsorbent trap. The quartz fiber filter was used to collect particle-bound pollutants, and the XAD-2 adsorbent resin was used for trapping vapor-phase contaminants. Detailed information regarding sample collection can be found in the Supplementary material.

Three to five stack gas samples were collected from each plant. The gas volume for each sample was about $2-3 \mathrm{~m}^{3}$, and the total volume collected from each plant was about 7-15 $\mathrm{m}^{3}$ (Table 1 ). The total sampling time for each process was 9-15 h. All samples were tightly wrapped in aluminum foil to minimize contamination and loss. At the end of the sampling trip, the samples were immediately transferred to a refrigerator, and stored until they could be analyzed.

\subsection{Preparation and analysis of stack gas samples}

Analysis of PCNs was carried out using isotope dilution high resolution gas chromatography/high resolution mass spectrometry (HRGC/HRMS) as previously described (Guo et al., 2008). Briefly, the samples were spiked with known amounts of ${ }^{13} \mathrm{C}_{10}-\mathrm{PCN}$ internal standards (ECN-5102, Tetra-Octa PCN Mixture, Cambridge Isotope Laboratories, USA) and Soxhlet-extracted for about $24 \mathrm{~h}$. The extracts were then concentrated in a rotary evaporator. The concentrated sample extracts were subjected to clean-up using a multilayer silica gel column and a basic alumina column. Finally, the eluted fractions were reduced to about $20 \mu \mathrm{L}$ in a rotary evaporator under a gentle stream of nitrogen. Prior to injection into the HRGC/HRMS, ${ }^{13} \mathrm{C}_{10}$-labeled PCN injection standards (ECN-5260, Cambridge Isotope Laboratories, USA) were added to enable calculation of the recovery.

PCNs analysis was carried out using a Trace GC coupled to a DFS mass spectrometer (Thermo Fisher Scientific, USA). A DB-5 fused silica capillary column $(60 \mathrm{~m} \times 0.25 \mathrm{~mm}$ i.d. $\times 0.25 \mu \mathrm{m})$ was used to separate the congeners. The mass range of the mass spectrometer (MS) was calibrated using perfluorotributyl amine (PFTBA), and the MS was tuned and operated at around 10000 resolution with $45 \mathrm{eV}$ EI energy. A selected ion-monitoring (SIM) mode was used for data acquisition.

Single PCN congeners for use as analytical standards are lacking (less than half of the 75 congeners were commercially available); therefore, identification of all 75 PCN congeners has proved difficult and remains uncertain (Helm and Bidleman, 2003). In the present study, peaks were identified based on their retention times compared with those of available individual standards, and on the ion ratios. The elution order of the PCN congeners on the DB- 5 column was also taken into account (Schneider et al., 1998; Abad et al., 1999). Peaks were quantified if the target/qualifier ion ratios were within $15 \%$ of the theoretical values. The limits of detection (LOD) varied from 0.1 to $5.0 \mathrm{pg} \mathrm{m}^{-3}$ for the different samples. The recovery of ${ }^{13} \mathrm{C}_{10}$-labeled PCN standards was $35-127 \%$. Blank experiments were carried out for every batch of samples. The concentration of monochlorinated and dichlorinated congeners in the blanks was higher than their LODs, but were lower than $5 \%$ of that in the samples. The PCN concentration in the samples was not corrected using the blank values in this study. Detailed information regarding sample preparation, analysis, and quality control can be found in the Supplementary material. 
Table 1

Basic information regarding the collected samples and the investigated sintering plants.

\begin{tabular}{clcllrl}
\hline Plants & $\begin{array}{l}\text { Number } \\
\text { of } \\
\text { samples }\end{array}$ & $\begin{array}{l}\text { Total } \\
\text { volume of } \\
\text { samples } \\
\left(\mathrm{m}^{3}\right)\end{array}$ & $\begin{array}{l}\text { Output } \\
\text { rate } \\
\left(\mathrm{t} \mathrm{h}^{-1}\right)\end{array}$ & $\begin{array}{l}\text { Scale of } \\
\text { sintering } \\
\text { bed }\left(\mathrm{m}^{2}\right)\end{array}$ & $\begin{array}{l}\text { Flow rate } \\
\left(\mathrm{m}^{3} \mathrm{~h}^{-1}\right)\end{array}$ & $\begin{array}{l}\text { Dust } \\
\text { arrestor }\end{array}$ \\
\hline IOS-1 & 5 & 12.0 & 320 & 265 & 465300 & ESP $^{\mathrm{a}}$ \\
IOS-2 & 3 & 8.9 & 600 & 450 & 463800 & ESP \\
IOS-3 & 3 & 12.0 & 600 & 300 & 328600 & ESP \\
IOS-4 & 4 & 8.7 & 102 & 78 & 460200 & ESP \\
IOS-5 & 5 & 15.5 & 158 & 105 & 318800 & ESP \\
IOS-6 & 3 & 7.1 & 480 & 328 & 600300 & ESP \\
IOS-7 & 5 & 9.5 & 500 & 265 & 1015900 & ESP \\
IOS-8 & 3 & 9.7 & 500 & 400 & 593800 & ESP \\
IOS-9 & 5 & 10.9 & 200 & 90 & 356100 & ESP \\
\hline
\end{tabular}

a Electrostatic precipitator.

\section{Results and discussion}

\subsection{Concentration of PCNs emitted by the investigated sintering processes}

Under the Stockholm Convention on POPs, national inventories and emission factors have been produced for PCDD/Fs in many countries and regions. However, data regarding the inventory and emission factors for PCNs is lacking. Iron ore sintering processes are currently one of the four dominant sources of PCDD/Fs in China. However, data regarding PCN emissions from iron ore sintering process are scarce. Therefore, to evaluate PCN emissions, nine typical sintering plants were identified and PCN emissions quantified.

The concentrations of PCN congeners in stack gas samples were all higher than their corresponding LODs. In this study, the TEQPCN of PCNs was defined by the sum of the products of the concentration of each congener multiplied by its RPF reported by Noma et al. (2004). The concentrations and $\mathrm{TEQ}_{\mathrm{PCN}}$ of the PCNs are summarized in Table 2. The average and medium concentrations of PCNs were 169 and $74 \mathrm{ng} \mathrm{m}^{-3}$ (range: $3-983 \mathrm{ng} \mathrm{m}^{-3}$ ), respectively, and the mean and medium TEQ $\mathrm{PCN}_{\mathrm{P}}$ were 3.65 and $1.4 \mathrm{pg}^{\mathrm{TE}} \mathrm{PCN}_{\mathrm{PCN}} \mathrm{m}^{-3}$, respectively (range: $0.4-23.3 \mathrm{pg} \mathrm{TEQ}_{\mathrm{PCN}} \mathrm{m}^{-3}$ ). The majority of data regarding PCN emissions have been derived from waste incineration, secondary metal smelting, and coking processes (Noma et al., 2006; Sakai et al., 2006; Jansson et al., 2008; Ba et al., 2010; Liu et al., 2010). The results of the present study show that the concentrations and $\mathrm{TEQ}_{\mathrm{PCN}}$ of PCNs released from iron ore sintering processes were generally lower than those reported for waste incineration and secondary metal smelting, and comparable with those from coking processes.

The PCN concentration measured at plant IOS-9 was clearly higher than that at the other plants. The raw materials, techniques,

Table 2

Average concentrations, emission factors and chlorination degrees of PCNs.

\begin{tabular}{|c|c|c|c|c|c|}
\hline \multirow[t]{2}{*}{ Plants } & \multicolumn{2}{|c|}{ Concentration } & \multicolumn{2}{|c|}{ Emission factor } & \multirow{2}{*}{$\begin{array}{l}\text { Degree of } \\
\text { chlorination }^{\mathrm{a}}\end{array}$} \\
\hline & $n g m^{-3}$ & pg TEQ $Q_{P C N} m^{-3}$ & $\mu \mathrm{g} \mathrm{t}^{-1}$ & ng TEQ ${ }_{P C N} t^{-1}$ & \\
\hline IOS-1 & 74 & 1.4 & 107 & 2.0 & 1.7 \\
\hline IOS-2 & 57 & 0.9 & 44 & 0.7 & 1.5 \\
\hline IOS-3 & 79 & 1.7 & 44 & 1.0 & 2.2 \\
\hline IOS-4 & 3 & 0.4 & 14 & 1.7 & 2.3 \\
\hline IOS-5 & 178 & 2.1 & 360 & 4.2 & 2.0 \\
\hline IOS-6 & 109 & 1.6 & 137 & 2.0 & 2.1 \\
\hline IOS-7 & 23 & 1.0 & 46 & 2.0 & 2.4 \\
\hline IOS-8 & 15 & 0.5 & 18 & 0.5 & 2.3 \\
\hline IOS-9 & 983 & 23.3 & 1749 & 41.5 & 1.7 \\
\hline
\end{tabular}

a Calculated as $\sum\left[\left(\right.\right.$ Homologue sum $\left./ \sum \mathrm{PCNs}\right) \times$ No. of $\left.\mathrm{Cl}\right]$. and end-of-pipe treatment are important factors for the formation and release of POPs (Xhrouet and De Pauw, 2004; Aries et al., 2006). Furthermore, the influence of the raw materials on dioxin formation during sintering processes has been studied in detail (Xhrouet and De Pauw, 2004). The results showed that dust accounted for $10 \%$ of the raw material collected in the electrostatic precipitator, which lead to a 1000 -fold increase in the amount of $\mathrm{PCDD} / \mathrm{Fs}$ formed. In the present study, the fraction of recycled material within the raw materials at plant IOS-9 $(>20 \%)$ was much higher than most of that at the other plants, which might account for the higher concentration of PCNs. Further studies regarding the impact of raw materials and techniques on PCN levels may lead to a reduction in $\mathrm{PCN}$ emissions from sintering processes.

\subsection{Characteristics of the PCN emissions}

Hierarchical cluster analysis (HCA) has been widely used to analyze the profiles of POP emissions from industrial sources (Oh et al., 2007; Liu et al., 2010). In the present study, discrepancies in PCN patterns between the investigated plants were observed. Therefore, HCA was used to evaluate the distribution pattern, as well as any possible grouping of emissions characteristics. HCA was performed using SPSS 16.0 software using a cluster method incorporating "between groups" linking with squared Euclidean distances.

The resulting dendrogram is shown in Fig. 1. Three main clusters are evident. Cluster 1 comprised plants IOS-3, IOS-6, IOS-8, IOS-4, and Cluster 2 comprised plants IOS-1, IOS-2, IOS-9. Plants IOS-5 and IOS-7 belonged to Cluster 3. The homolog pattern for the PCNs in these three clusters is shown in Fig. 2. Low-chlorinated homologs comprising MonoCN, DiCN and TriCN were highly dominant in all three clusters. MonoCN and TriCN homologs were the most abundant in Cluster 1, followed by the DiCN homolog. The MonoCN homolog was the dominant form in Cluster 2, accounting for about $65 \%$ of the total. DiCN was the major homolog present in Cluster 3, comprising about 55\% of the total. These results indicate clearly different PCN homolog patterns at the investigated plants. The degree of chlorination is the sum of the homolog percentages multiplied by the number of substituted chlorines within the homologs. It is normally an important parameter that indicates the distribution of different chlorinated homologs (Jansson et al., 2008). In this study, the degree of PCN chlorination was calculated to be 1.5-2.4. The average degree of chlorination was 2.2 in Cluster $1,1.6$ in Cluster 2, and 2.2 in Cluster 3. These values are comparable with those from municipal solid waste (MSW) combustion (Jansson et al., 2008) and coking processes (Liu et al., 2010).

Many studies have identified certain congeners that are absent, or occur at low levels, in commercial PCN and PCB mixtures, but are very abundant in thermal-related processes (Schneider et al., 1998; Abad et al., 1999; Yamashita et al., 2000; Meijer et al., 2001). These congeners are classified as thermal-related PCN congeners, and are useful for differentiating between PCN emissions from thermal related industries and evaporative emissions from the historical use of PCN or PCB mixtures. The ratios of selected PCN congeners may indicate possible sources (Helm and Bidleman, 2003; Helm et al., 2004; Noma et al., 2004). For example, the ratio of CN73CN74 $\left(R_{73 / 74}\right)$ varies in different source samples, with values $<1$ for Halowaxes (Noma et al., 2004), but $>1$ in stack gases or fly ash samples from thermal-related sources (Abad et al., 1999; Takasuga et al., 2004; Jansson et al., 2008). The ratio of CN73-CN74 in PCB mixtures varied greatly depending on the type of commercial PCB mixture. Similarly Helm et al. determined the ratio of CN52 to the sum of CN52 and CN60 ( $\left.\mathrm{R}_{52 /(52+60)}\right)$, and CN66 to the sum of CN66 and $\mathrm{CN} 67\left(\mathrm{R}_{66 /(66+67)}\right)$ in air, Halowax, PCB mixtures, and fly ash samples, which were used to interpret the source of PCNs in air (Helm and Bidleman, 2003; Helm et al., 2004). In the present study, the ratios of several characteristic PCN congeners were determined 


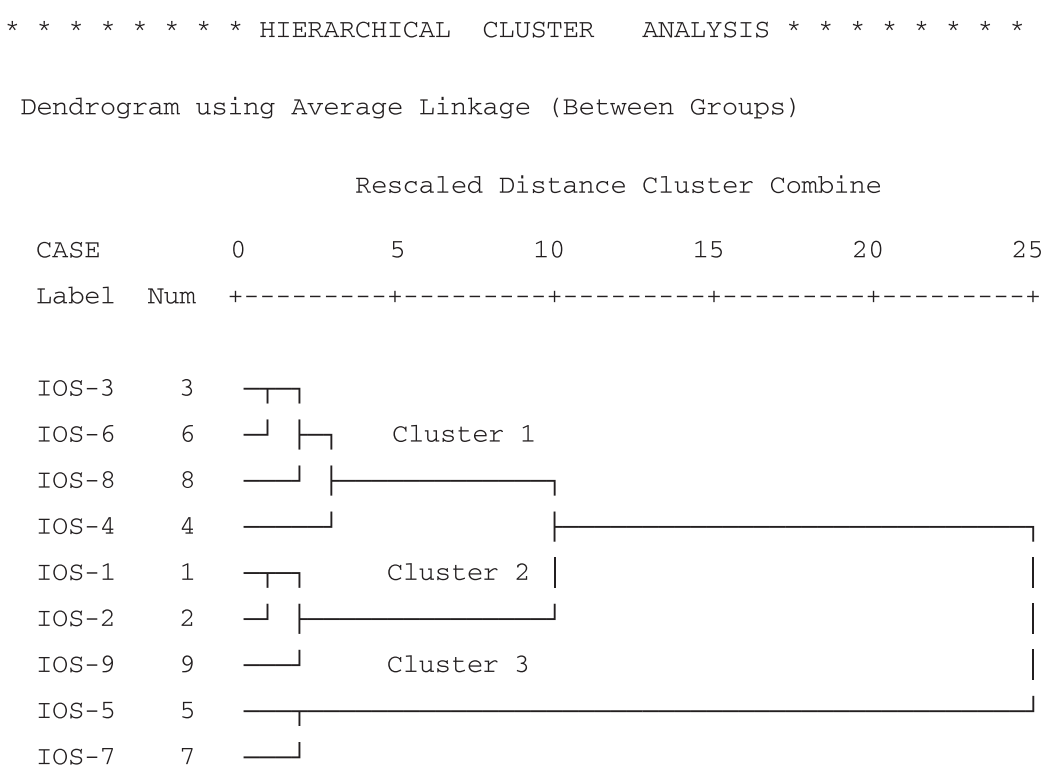

Fig. 1. Hierarchical dendrogram of HCA analyses.

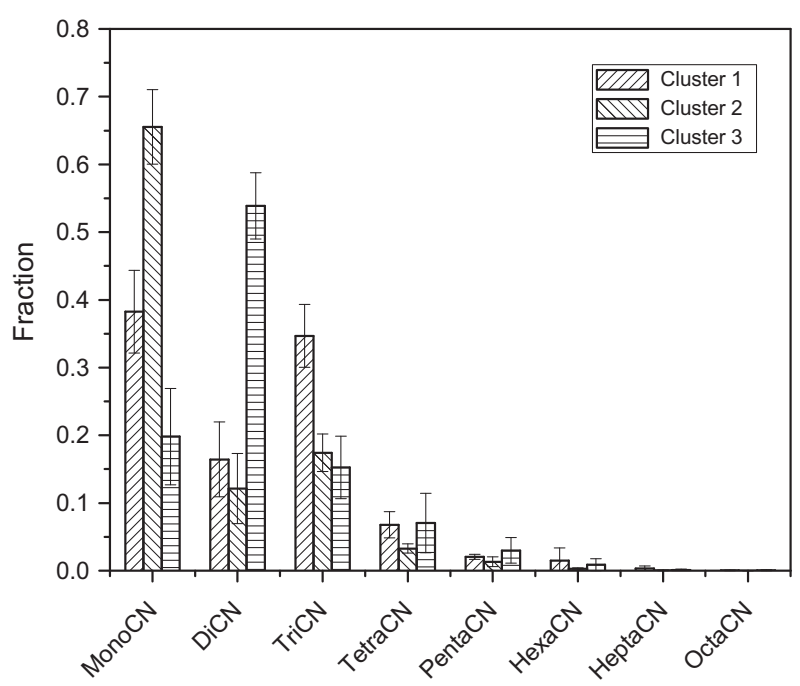

Fig. 2. Representative homolog profiles for the PCNs in three clusters.

for iron ore sintering processes and are presented in Fig. 3. These PCN profiles are clearly distinct from those resulting from the historic production of PCN or PCB mixtures (Schneider et al., 1998; Helm and Bidleman, 2003; Helm et al., 2004), which may provide diagnostic information for identifying specific PCN sources.

With regard to the toxicity patterns of PCNs, the relative toxic contributions of PCN congeners, for which RPF relative to 2378TeCDD have been suggested (Noma et al., 2004), are shown in Fig. 4. The dominant toxic congeners were CN66/67, CN73 and CN63, owing to their relatively high RPF compared with those of other PCN congeners. CN1 and CN2 were the dominant toxic contributors as they were present at much higher concentrations than other PCN congeners. In general, the different TEQ ${ }_{P C N}$ patterns were observed for the PCN congeners from different plants, which might be helpful for identifying PCN sources.

\subsection{Estimation of PCN emissions from the iron ore sintering processes}

Emission factors may be useful for estimating the total emissions of a given pollutant from a given source based on limited data

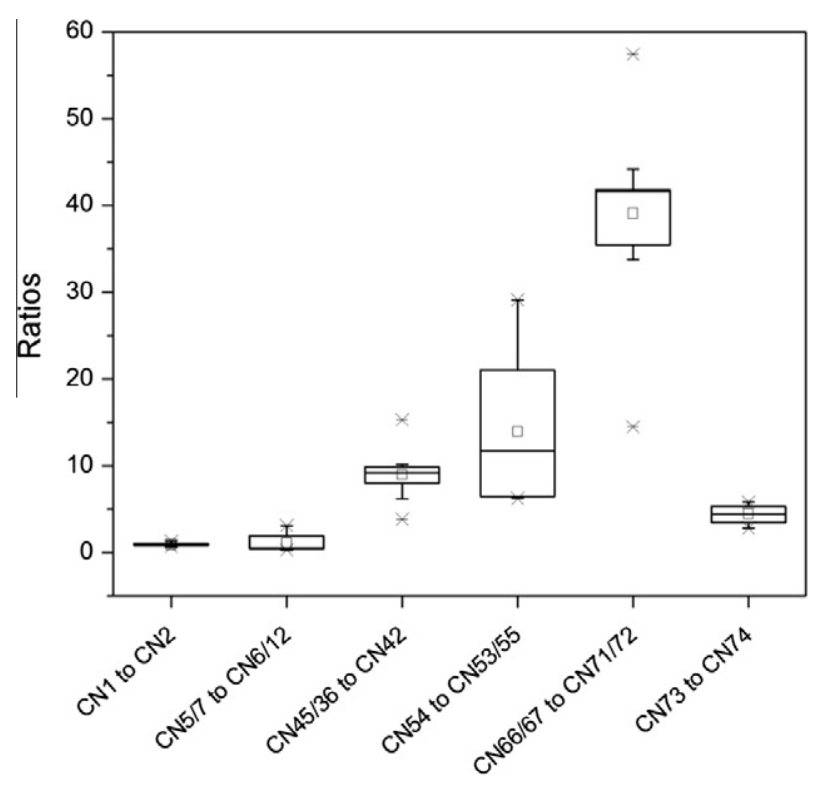

Fig. 3. Ratio of selected PCN congeners from the iron ore sintering processes.

(Liu et al., 2009). In the present study, the emission factors and emission amounts were calculated using to the following equations:

Emission factor $=\frac{\text { Flow rate } \times \text { Concentration }}{\text { Output rate }(\text { or Feeding rate })}$

\section{Emission amount $=$ Activity level $\times$ Emission factor}

PCN emission factors from the sintering process were derived from the obtained data and are shown in Table 2 . The emission factors ranged from 0.5 to $41.5 \mathrm{ng} \mathrm{TEQ}_{\mathrm{PCN}} \mathrm{t}^{-1}\left(14-1749 \mu \mathrm{g} \mathrm{t}^{-1}\right)$; the data set was very large. Methods used to evaluate the emission factors from a large data set were reported recently, and the geometric mean was adopted for evaluating the emission factors (Black et al., 2012). For iron ore sintering processes, the geometric mean of the emission factors was $2.1 \mathrm{ng} \mathrm{TEQ}_{\mathrm{PCN}} \mathrm{t}^{-1}\left(84 \mu \mathrm{g} \mathrm{t}^{-1}\right)$. The an- 


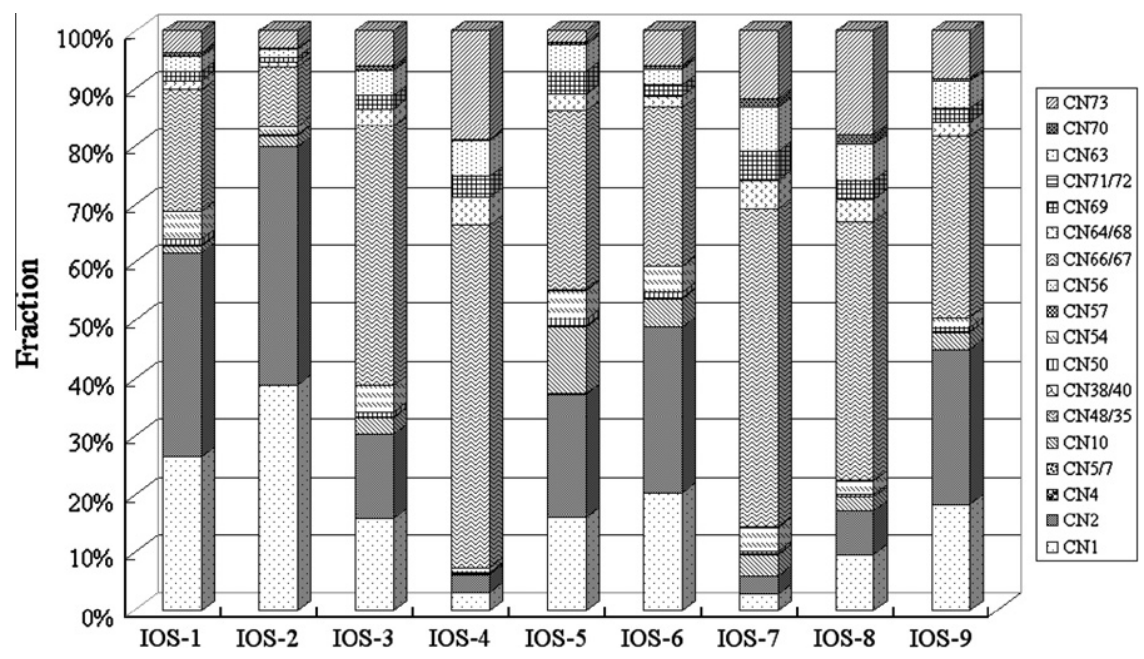

Fig. 4. $T E Q_{P C N}$ contribution of individual congeners to the total $P C N$ TEQ $P$ PCN.

nual output of sintering ore in China was about 662 million tonnes in 2009; thus, the preliminary estimate of the annual PCN emissions from Chinese sintering processes is about $1390 \mathrm{mg} \mathrm{TEQ}_{\mathrm{PCN}}$.

Emission factors and annual emission levels for PCNs from secondary nonferrous smelting and coking processes were reported in detail by Ba et al. (2010) and Liu et al. (2010), respectively. The average annual emissions for PCNs from secondary copper, aluminum, zinc and lead smelting in China were estimated to be $860,390,10$ and $9 \mathrm{mg} \mathrm{TEQ}_{\mathrm{PCN}}$, respectively, in China. The average annual emissions for PCNs from the coking process were estimated to be $337 \mathrm{mg} \mathrm{TEQ}_{\mathrm{PCN}}$. Thus, the present, preliminary investigation indicates that iron ore sintering processes might be an important source of PCNs in China.

\section{Conclusion}

In summary, the emission levels and profiles of PCNs from nine typical iron ore sintering processes were identified and quantified. The characteristics of the PCNs were identified and compared with those from other sources, and provide useful information for identifying specific sources of PCNs. The PCN emissions factors were derived from the obtained data, and the annual emissions from sintering processes were estimated, which will be helpful for developing a PCN inventory. The preliminary estimations suggest that iron ore sintering processes might be an important source of PCNs in China.

\section{Acknowledgments}

Financial support for this work was provided by the National 973 program (No. 2009CB421606) and the National Natural Science Foundation of China (Nos. 21107123, 21037003).

\section{Appendix A. Supplementary material}

Supplementary data associated with this article can be found, in the online version, at http://dx.doi.org/10.1016/j.chemosphere. 2012.05.101.

\section{References}

Abad, E., Caixach, J., Rivera, J., 1999. Dioxin like compounds from municipal waste incinerator emissions: assessment of the presence of polychlorinated naphthalenes. Chemosphere 38, 109-120.

Abad, E., Martinez, K., Caixach, J., Rivera, J., 2004. Polychlorinated dibenzo-p-dioxin/ polychlorinated dibenzofuran releases into the atmosphere from the use of secondary fuels in cement kilns during clinker formation. Environ. Sci. Technol. $38,4734-4738$.

Aries, E., Anderson, D.R., Fisher, R., Fray, T.A.T., Hemfrey, D., 2006. PCDD/F and "dioxin-like" PCB emissions from iron ore sintering plants in the UK. Chemosphere 65, 1470-1480.

Ba, T., Zheng, M.H., Zhang, B., Liu, W.B., Su, G.J., Liu, G.R., Xiao, K., 2010. Estimation and congener-specific characterization of polychlorinated naphthalene emissions from secondary nonferrous metallurgical facilities in China. Environ. Sci. Technol. 44, 2441-2446.

Bidleman, T.F., Helm, P.A., Braune, B.M., Gabrielsen, G.W., 2010. Polychlorinated naphthalenes in polar environments - a review. Sci. Total Environ. 408, 29192935.

Black, R., Meyer, C., Touati, A., Gullett, B., Fiedler, H., Mueller, J., 2012. Emission factors for PCDD/PCDF and dl-PCB from open burning of biomass. Environ. Int. $38,62-66$

Blankenship, A.L., Kannan, K., Villalobos, S.A., Villeneuve, D.L., Falandysz, J., Imagawa, T., Jakobsson, E., Giesy, J.P., 2000. Relative potencies of individual polychlorinated naphthalenes and halowax mixtures to induce Ah receptormediated responses. Environ. Sci. Technol. 34, 3153-3158.

Cieplik, M.K., Carbonell, J.P., Munoz, C., Baker, S., Kruger, S., Liljelind, P., Marklund, S. Louw, R., 2003. On dioxin formation in iron ore sintering. Environ. Sci. Technol. 37, 3323-3331.

Domingo, J.L., 2004. Polychlorinated naphthalenes in animal aquatic species and human exposure through the diet: a review. J. Chromatogr. A 1054, 327334.

Falandysz, J., 1998. Polychlorinated naphthalenes: an environmental update. Environ. Pollut. 101, 77-90.

Guo, L., Zhang, B., Xiao, K., Zhang, Q.H., Zheng, M.H., 2008. Levels and distributions of polychlorinated naphthalenes in sewage sludge of urban wastewater treatment plants. Chin. Sci. Bull. 53, 508-513.

Harner, T., Shoeib, M., Gouin, T., Blanchard, P., 2006. Polychlorinated naphthalenes in Great lakes air: assessing spatial trends and combustion inputs using PUF disk passive air samplers. Environ. Sci. Technol. 40, 5333-5339.

Helm, P.A., Bidleman, T.F., 2003. Current combustion-related sources contribute to polychlorinated naphthalene and dioxin-like polychlorinated biphenyl levels and profiles in air in Toronto, Canada. Environ. Sci. Technol. 37, 1075-1082.

Helm, P.A., Bidleman, T.F., Li, H.H., Fellin, P., 2004. Seasonal and spatial variation of polychlorinated naphthalenes and non-/mono-ortho-substituted polychlorinated biphenyls in arctic air. Environ. Sci. Technol. 38, 5514-5521.

Iino, F., Imagawa, T., Takeuchi, M., Sadakata, M., 1999. De novo synthesis mechanism of polychlorinated dibenzofurans from polycyclic aromatic hydrocarbons and the characteristic isomers of polychlorinated naphthalenes. Environ. Sci. Technol. 33, 1038-1043.

Imagawa, T., Lee, C.W., 2001. Correlation of polychlorinated naphthalenes with polychlorinated dibenzofurans formed from waste incineration. Chemosphere 44, 1511-1520.

Jansson, S., Fick, J., Marklund, S., 2008. Formation and chlorination of polychlorinated naphthalenes (PCNs) in the post-combustion zone during MSW combustion. Chemosphere 72, 1138-1144.

Kannan, K., Imagawa, T., Blankenship, A.L., Giesy, J.P., 1998. Isomer-specific analysis and toxic evaluation of polychlorinated naphthalenes in soil, sediment and biota collected near the site of a former chlor-alkali plant. Environ. Sci. Technol. 32, 2507-2514.

Kannan, K., Kober, J.L., Kang, Y.S., Masunaga, S., Nakanishi, J., Ostaszewski, A., Giesy, J.P., 2001. Polychlorinated naphthalenes, biphenyls, dibenzo-p-dioxins, and dibenzofurans as well as polycyclic aromatic hydrocarbons and alkylphenols in sediment from the Detroit and Rouge Rivers, Michigan, USA. Environ. Toxicol. Chem. 20, 1878-1889.

Lerche, D., van de Plassche, E., Schwegler, A., Balk, F., 2002. Selecting chemical substances for the UN-ECE POP protocol. Chemosphere 47, 617-630. 
Liu, G.R., Zheng, M.H., Liu, W.B., Wang, C.Z., Zhang, B., Gao, L.R., Su, G.J., Xiao, K., Lv, P., 2009. Atmospheric emission of PCDD/Fs, PCBs, hexachlorobenzene, and pentachlorobenzene from the coking industry. Environ. Sci. Technol. 43, 91969201.

Liu, G.R., Zheng, M.H., Lv, P., Liu, W.B., Wang, C.Z., Zhang, B., Xiao, K., 2010 Estimation and characterization of polychlorinated naphthalene emission from coking industries. Environ. Sci. Technol. 44, 8156-8161.

Meijer, S.N., Harner, T., Helm, P.A., Halsall, C.J., Johnston, A.E., Jones, K.C., 2001. Polychlorinated naphthalenes in UK soils: time trends, markers of source, and equilibrium status. Environ. Sci. Technol. 35, 4205-4213.

Noma, Y., Yamamoto, T., Giraud, R., Sakai, S., 2006. Behavior of PCNs, PCDDs, PCDFs, and dioxin-like PCBs in the thermal destruction of wastes containing PCNs. Chemosphere 62, 1183-1195.

Noma, Y., Yamamoto, T., Sakai, S.I., 2004. Congener-specific composition of polychlorinated naphthalenes, coplanar PCBs, dibenzo-p-dioxins, and dibenzofurans in the halowax series. Environ. Sci. Technol. 38, 1675-1680.

Oh, J.E., Gullett, B., Ryan, S., Touati, A., 2007. Mechanistic relationships among PCDDs/Fs, PCNs, PAHs, CIPhs, and CIBzs in municipal waste incineration. Environ. Sci. Technol. 41, 4705-4710.

Park, H., Kang, J.H., Baek, S.Y., Chang, Y.S., 2010. Relative importance of polychlorinated naphthalenes compared to dioxins, and polychlorinated biphenyls in human serum from Korea: contribution to TEQs and potential sources. Environ. Pollut. 158, 1420-1427.
Sakai, S., Yamamoto, T., Noma, Y., Giraud, R., 2006. Formation and control of toxic polychlorinated compounds during incineration of wastes containing polychlorinated naphthalenes. Environ. Sci. Technol. 40, 2247-2253.

Schneider, M., Stieglitz, L., Will, R., Zwick, G., 1998. Formation of polychlorinated naphthalenes on fly ash. Chemosphere 37, 2055-2070.

Takasuga, T., Inoue, T., Ohi, E., Kumar, K.S., 2004. Formation of polychlorinated naphthalenes, dibenzo-p-dioxins, dibenzofurans, biphenyls, and organochlorine pesticides in thermal processes and their occurrence in ambient air. Arch. Environ. Contam. Toxicol. 46, 419-431.

Villeneuve, D.L., Kannan, K., Khim, J.S., Falandysz, J., Nikiforov, V.A., Blankenship A.L., Giesy, J.P., 2000. Relative potencies of individual polychlorinated naphthalenes to induce dioxin-like responses in fish and mammalian in vitro bioassays. Arch. Environ. Contam. Toxicol. 39, 273-281.

Weber, R., Iino, F., Imagawa, T., Takeuchi, M., Sakurai, T., Sadakata, M., 2001 Formation of PCDF, PCDD, PCB, and PCN in de novo synthesis from PAH mechanistic aspects and correlation to fluidized bed incinerators. Chemosphere 44, 1429-1438.

Xhrouet, C., De Pauw, E., 2004. Formation of PCDD/Fs in the sintering process: influence of the raw materials. Environ. Sci. Technol. 38, 4222-4226.

Yamashita, N., Kannan, K., Imagawa, T., Miyazaki, A., Giesy, J.P., 2000 Concentrations and profiles of polychlorinated naphthalene congeners in eighteen technical polychlorinated biphenyl preparations. Environ. Sci. Technol. 34, 4236-4241. 